RU Специфика взаимосвязи перцептов, репрезентаций, фреймов и концептов в ментальной модели мира

\begin{abstract}
Хахалова С. А.
Аннотация. Цель исследования - определить специфику взаимосвязи перцептов, репрезентаций, фреймов и концептов в ментальной модели мира. В статье приведён аналитический обзор основных достижений российской и зарубежной когнитивной науки по вопросам изучения способов хранения и репрезентации знания в сознании человека. Научная новизна исследования заключается в том, что впервые проведен анализ фрейма «опасность» с использованием методики стратегических вопросов. В результате выявлено, что ментальная модель мира подвержена манипуляции и формируется вокруг концептов, структурированных фреймами, и базируется на антиномиях «конструкция vs реконструкция», «перцепция vs репрезентация».
\end{abstract}

\title{
EN Specificity of Interaction of Percepts, Representations, Frames and Concepts in Mental World Model
}

\author{
Khakhalova S. A.
}

\begin{abstract}
The paper aims to reveal specificity of interaction of percepts, representations, frames and concepts in human consciousness. The article provides an analytical survey of foreign and domestic studies on mechanisms of human cognition (knowledge storage and knowledge representation). Scientific originality of the research lies in the fact that the author for the first time analyses the frame "threat" using the strategic questioning method. The research findings are as follows: the author shows that the mental world model is a dynamic one; it focuses on concepts and is based on the antinomies "construction vs reconstruction”, "perception vs representation".
\end{abstract}

\section{Введение}

Актуальность темы исследования обусловлена необходимостью объяснить сложность работы человеческой мысли, участвующей в процессах восприятия, переработки, кодирования и декодирования языковой информации, поступающей извне во внутренний механизм когниции.

Задачи, которые поставлены для решения в данной статье, формулируются таким образом: дать краткий обзор разных точек зрения на трактовку процессов структурирования знания, определить способы когнитивной и языковой реконструкции поступающей информации, дать характеристику ментальных моделей мира, провести анализ фрейма сохранение в составе концепта ЗДОРОВЬЕ с использованием метода стратегических вопросов, выявить манипулятивную роль фреймов и концептов в ментальной модели мира.

Для решения задач исследования используются метод сопоставительного анализа, метод сравнительного анализа теоретических положений когнитивной лингвистики, метод компонентного анализа, метод анализа словарных дефиниций, фреймовый анализ.

Теоретической базой исследования послужили публикации отечественных (Ю. С. Степанов, Е. С. Кубрякова, Д. С. Лихачёв, И. А. Стернин, В. И. Карасик, З. Д. Попова, С. Г. Воркачев и др.) и зарубежных авторов (Дж. Лайонс, Э. Сэпир, Б. Уорф, А. Цим, М. Шварц, М. Бирвиш, А. Цим, М. Шварц, С. Фраас, Э. Рош, С. Палмер, Р. Лангакер, Дж. Лакофф и др.) по проблемам исследования языковых картин мира и идеализированных когнитивных моделей.

Практическая значимость работы: материалы исследования могут быть использованы в вузах гуманитарного направления при изучении спецкурсов и спецсеминаров по теоретическому, сравнительному языкознанию. Полученные данные могут найти применение в процессе учебно-методической деятельности при создании учебных пособий для подготовки аспирантов по направлению «Языкознание и литературоведение», специальности «Теория языка». 


\section{Краткий обзор разных точек зрения на трактовку процессов структурирования знания}

Лингвистическая мысль прошла достаточно длительный этап становления, в процессе которого возникли разные парадигмальные взгляды на трактовку когнитивных процессов, лежащих в основе коммуникативного взаимодействия членов социума. Результаты исследований когнитивной лингвистики показывают, что когнитивные процессы структурированы комплексно [9; 15; 27; 36]. Концептуальная парадигма исследований [3; 7; 14; 15; 20; 21] позволяет сделать вывод о том, что разнообразие концептов, хранящихся в памяти [8], структурировано по-разному.

С одной стороны, они состоят в части структуры из ядра и периферии [13], с другой стороны, организованы в некие иерархические цепочки концептуальных признаков [1; 2; 31], с третьей стороны, они анализируются как трёхмерные образования [5; 6; 12]. Если исходить из того, что когнитивный процесс есть процесс, базирующийся на имеющемся (схематизированном) знании [16, с. 153-154; 18, с. 214; 25, р. 4], то особо важную роль играют в этом процессе концепты, у которых есть имена [4].

Каждое имя даёт доступ к тому или иному концепту, представляющему собой своего рода содержательный потенциал для семантических единиц, которые избирательно связывают концептуальную информацию с языковыми формами [32, S. 16]. Так структурируется концептуальное знание, которое извлекается из долговременной памяти благодаря хранению неких опытных единиц в виде элементов обширных единиц знания, составляющих: а) фреймы, б) идеализированные когнитивные модели, в) схемы, г) домены, д) семантические сети, е) репрезентации, ж) ментальные пространства. Все они подлежат когнитивной обработке в виде ментальных репрезентаций [28], коими могут быть когнитивные модели мира на уровне мыслительной абстракции как результат когнитивно-конструктивных достижений индивидуума в его сознании.

\section{Способы когнитивной и языковой реконструкции поступающей информации}

Когнитивная реконструкция знания в сознании человека связана с умением реконструировать некие модели в онтологии разных миров - обыденного (материального) мира и ментального мира. Причём ментальный мир состоит из отображенного мира (represented world) и отображаемого мира (representing world) [30, p. 262]. Скорее всего, речь надо вести, во-первых, о конструируемом, существующем вне человека мире, а вовторых, о реконструируемом внутри него мире [Ibidem, p. 259-303].

В результате существования множественных миров наблюдаются антиномии типа: «конструкция vs реконструкция», «презентация vs репрезентация», «перцепт vs репрезентация», свидетельствующие об асимметрии между планом выражения и планом отражения, планом восприятия и планом сохранения информации.

Упомянутые выше типы асимметрии проявляются в результате существующей дихотомии ПАМяТЬ ВОСПРИЯТИЕ и являются следствием наличия в долговременной памяти человека схем высшей степени абстракции [36, S. 39], которые хранятся в долговременной памяти и представляют накопления прошлого опыта - репрезентации (Repräsentationen) - продукты познания, которые можно классифицировать на индивидуальные и групповые.

А в кратковременной (рабочей) памяти, связанной с процессом восприятия, формируются схемы новых обретений - перцепты (Perzepte), которые структурируют внешний модус когниции. Он противопоставлен внутреннему модусу когниции [32; 36], который хранит набор определенных репрезентаций в долговременной памяти человека. Если перцепты представляют собой единицы восприятия в виде феноменологического или чувственного понятия, вызываемого сенсорными раздражителями - зрительными, вкусовыми, тактильными, слуховыми анализаторами и обонянием, то репрезентации хранят приобретенное знание. Между первыми и вторыми наблюдается определенная корреляция. Репрезентации имеют референтов в ментальной модели мира внешнего модуса когниции в виде перцептов, которые могут мотивировать или не мотивировать репрезентации [36, S. 39].

Таким образом, при трансформации сенсорного раздражителя в факт сознания активизируются структуры из предыдущего практического опыта, которые называются репрезентациями. Оба ментальных мира отображенный и отображаемый - являются результатом управляемого сознанием процесса реконструкции перцептов [30, p. 262] и представляют собой два аспекта когнитивно-реконструктивных достижений мыслительной деятельности человека.

\section{Ментальные модели мира}

Совокупность всех перцептов составляет отображаемую ментальную модель мира (мир р), которая поддается познанию через восприятие и которую можно трактовать как обыденный мир, присутствующий во внешнем модусе когниции. Множество всех единиц репрезентативного познания во внутреннем модусе когниции образует отображенную ментальную модель мира (мир м) [33, S. 44], которая представляет собой внутреннее состояние организма со всем его знанием, приобретенным опытным путем. Репрезентации в этой ментальной модели мира имеют своих референтов в перцептуальном пространстве [36, S. 40]. Так, например, при восприятии слова машина репрезентации мотивированы перцептами, имеющими отношение к функции 
(средство передвижения), и в то же время они могут быть и не мотивированными по отношению к величине, цвету, марке автомобиля, его мощности, объему двигателя, типу привода и т.д. Во внутреннем модусе когниции это может быть легковая, грузовая, седан, пикап, хэтчбэк, любого цвета, а во внешнем модусе когниции это сконструированное конкретное транспортное средство, имеющее определенные характеристики, отличающие его от другого такого же в одном ряду перцептов. Когда используется слово ИЛ-76, во внутреннем модусе когниции возникают репрезентации, не мотивированные перцептами, - самолет, артефакт, перевозит авиапассажиров, грузы, дальние расстояния, большая высота и т.д. Во внешнем модусе когниции обнаруживаются перцепты в виде когнитивных конструктов: а) грузовой, б) для транспортировки, в) особые цели, г) перевозка не авиапассажиров. Итак, перцепт - это единица восприятия в кратковременной памяти, составная часть отображаемой ментальной модели мира. Репрезентации, в отличие от перцептов, представляют собой концептуальные и ситуативные структуры знаний как чрезвычайно многообразные и изменчивые оперативные единицы долговременной памяти, составляющие отображенную ментальную модель мира.

\section{Ментальная модель мира: идентификация фрейма сохранение в концепте ЗДОРОВЬЕ}

Язык представляет собой концептуализацию на всех уровнях своей организации [Ibidem, S. 113]. Предположим, что ментальная модель мира во внутреннем модусе когниции представлена репрезентациями в виде концептов, с одной стороны, и в виде фреймов, с другой стороны. Тогда концепты репрезентируют знания о феноменах (состояния), фреймы репрезентируют знания о типизированных ситуациях (процессы), трактуются как формат репрезентации языкового знания [Ibidem, S. 41] и как форма активации знания, связанного с языком [22, S. 77]. Количество фреймов в долговременной памяти человека неисчислимо, поскольку каждый из них репрезентирует определенную «стереотипную ситуацию» [29, p. 244]. Подходим к выводу, что состояния и процессы должны характеризовать ментальную модель мира. Предположим, одним из состояний в этой ментальной модели мира является ЗДОРОВЬЕ (человека). Оно рассматривается как концепт, отличительной особенностью которого является его динамичность, репрезентированная в модификациях когнитивных признаков, мотивированных перцептами советского и постсоветского периодов жизнедеятельности человека в социуме $[11$, с. 14,16$]$. Нам представляется, что модификации когнитивных признаков структурированы во фреймах, и позволим предположить, что одним из таких фреймов является структура знания о типизированной ситуации сохранения здоровья. А теперь зададимся вопросом, может ли структура знания, актуализированная словом сохранение, в составе концепта ЗДОРОВЬЕ быть фреймом? Для ответа на этот вопрос предлагаем использовать методику фреймового анализа в виде набора стратегических вопросов [23, S. 16-27].

Вопрос 1. Что такое фрейм сохранение? Это структура знания о типизированной ситуации «как содержать здоровье в безопасности».

Вопрос 2. Из чего состоит фрейм сохранение? Он состоит из языкового знания и репрезентаций во внутреннем модусе когниции, из трёх номинативных слотов, два из которых наполнены прямым значением слова, а третий - переносным (метафорическим).

Вопрос 3. Какие характерные черты присущи фрейму сохранение? Для ответа на этот вопрос используем толковый словарь Ожегова в части анализа узуального значения слова, которое закреплено за названием фрейма [17]: этимологически слово восходит к глаголу хранить со значениями: 1) беречь, содержать где-нибудь в безопасности, в целости кого-то или что-то; 2) оберегать, защищать что-то; 3) (метафорическое значение) соблюдать, поддерживать, сохранять что-то. Например: гордый вид, печаль в сердце, на лице, молчание.

Вопрос 4. Какие функции выполняет и какую роль играет фрейм в познании? Фрейм сохранение выполняет функцию формирования семантической компетентности и манипулирования ассоциациями, образами, перцептами, презентациями в сознании человека.

Вопрос 5. Какие преимущества даёт употребление фрейма? Использование фрейма сохранение обеспечивает говорящего системой понятий, за которыми стоят определенные конфигурации, придающие понятиям коммуницируемые формы, например: сохранить здоровье, поддерживать здоровье, развить здоровье, здоровье для всех, бояться за своё здоровье, на здоровье деньги делать, поправить здоровье, улучшить здоровье [10].

Вопрос 6. Какие обязанности и запреты налагаются на фрейм сохранение? Он несовместим с конфигурациями подорвать здоровье, сэкономить на здоровье, разрушать здоровье и противопоставлен фрейму уничтожение.

Вопрос 7. Каким статусом обладает фрейм? Фрейм сохранение обладает статусом самостоятельного сценария.

Вопрос 8. Каким образом человек связан с фреймом сохранение в структуре концепта ЗДОРОВЬЕ? Он связан ассоциативной связью, косвенной анафоричностью, имплицитным речевым актом сохранить здоровье значит жить.

Вопрос 9. Когда и при каких условиях появляется фрейм? Фрейм сохранение в структуре концепта ЗДОРОВЬЕ появляется в условиях моделирования ментального мира и активизируется в условиях введения в коммуникативное языковое сообщество наряду с концептом ЗДОРОВЬЕ концепта САМОИЗОЛЯЦИЯ. Последний, репрезентируемый предложениями, может быть описан на основе определенного набора ментальных примитивов и определенного набора принципов комбинирования этих примитивов [19].

Вопрос 10. Какие фазы проходит фрейм сохранение в структуре концепта ЗДОРОВЬЕ? Фазы беречь, оберегать, хранить, сохранить формируют структуру знания о процессе (само)изоляции.

Вопрос 11. При каких условиях существует фрейм? При условии косвенной анафоричности и связности с концептом КОРОНАВИРУС, при условии, что не сам я себя изолирую, как свидетельствует первичное значение 
слова «самоизоляция», а меня изолируют от других людей. В этом моменте происходит подмена понятий, лежащая в основе манипулирования словами. Фрейм существует в условиях диктуемой извне необходимости в ментальном пространстве концепта ИЗОЛЯЦИЯ на основе набора ментальных примитивов я должен, от меня требуют, я сам не хочу, которые формируют директивный речевой акт. Концепт НЕЖЕЛАТЕЛЬНОЕ как характеристика изменения поведения человека остаётся имплицитным в ментальной модели мира памяти.

Вопрос 12. Какие условия способствуют продуктивности фрейма? По каким причинам это происходит? Изменения, происходящие во внешнем модусе когниции, в языке и речевой деятельности, познание и восприятие внешнего мира способствуют продуктивности фрейма.

Итак, структура знания, актуализированная словом сохранение, может претендовать на статус фрейма в контексте корреляции с концептом ЗДОРОВЬЕ и представляет собой схему высшей степени абстракции со статусом самостоятельного сценария «как содержать здоровье в безопасности» и имплицитным речевым актом сохранить здоровье - значит жить. Структуру фрейма составляют три номинативных слота. Фрейм сохранение обеспечивает человека системой понятий, за которыми стоят определенные конфигурации, придающие понятиям коммуницируемые формы, участвуя, таким образом, в процессе манипулирования репрезентациями в ментальной модели мира. Фрейм сохранение продуктивен, структурирует концепт ЗДОРОВЬЕ, наряду с другими фреймами, анализ которых не входит в задачи настоящей статьи. Перейдем к взаимосвязи ментальной модели мира с языковой деятельностью человека, которая оперирует инструментами, называемыми языковыми символами, языковыми знаками. Звуки и графемы, составляющие языковой инвентарь, представляют собой особый тип раздражителей, улавливаемых зрительными и слуховыми анализаторами. В 2020 году во внешнем модусе когниции появляется перцепт COVID-19, неизвестный до этого обывателю. Этот перцепт предъявлен человеку для дальнейшей когнитивной реконструкции и ментальной репрезентации в процессе познания. Этот путь достаточно долгий, но начинается он с декодирования значения, стоящего за языковым знаком, являющимся звуковым и зрительным раздражителем. Значение языкового знака можно декодировать как множество семантических признаков: а) болезнь; б) причина болезни - вирус; в) наименование вируса - coronavirus SARS-CoV-2; г) вирусная инфекция SARS COVID-2019; д) инфекционное заболевание; е) новый, ранее неизвестный коронавирус [24].

Анализ языкового материала в национальном газетном корпусе русского языка позволяет утверждать, что в ментальной модели мира внутреннего модуса когниции концепт ЗДОРОВЬЕ может быть структурирован фреймом сохранение, который активизируется в условиях введения в коммуникативное языковое сообщество перцепта COVID-19 и концепта САМОИЗОЛЯцИЯ и противопоставляется фрейму уничтожение. Анализ теоретического материала по проблеме позволяет подвести к выводу о том, что фрейм сохранение тождествен репрезентации сохранение и представлен в ментальной модели мира человека, познающего реалии сложного для него периода пандемии.

\section{Манипулятивная роль фреймов и концептов в ментальной модели мира}

Ментальная модель мира структурируется перцептами, репрезентациями, концептами, фреймами при условии, что часть этой модели имеет прототипический характер, а часть - индивидуально-специфический. Отсюда концепт ЗДОРОВЬЕ у каждого свой, концепт САМОИЗОЛЯЦИЯ также индивидуально специфичен, перцепт COVID-19 находится на пути когнитивной реконструкции в репрезентацию, в процессе познания, которое представляет собой прежде всего процесс концептуализации [36, S. 113], связанный с тем, что воспринятое переходит в переработанное и понятое, а понятое есть не что иное, как концептуализованное. А это предполагает, что на одном из этапов когнитивного развития произойдет устойчивое внедрение фрейма COVID-19 в структуру концепта ЗДОРОВЬЕ. А на пути когнитивной реконструкции из мира материального в мир ментальный, из отображаемого мира в мир отображенный перцепт COVID-19 подвергается механизму манипулирования, при котором фрейм опасность приобретает иное содержание.

Для различения этих двух ментальных миров М. Шварц предлагает использовать термин “Manipulation” (манипуляция). Проанализируем значение слова «манипуляция» в русском языке. Основное или первоначальное значение сводится к следующему. Оно возникло как книжное выражение и относится к сложному приёму, действию над чем-нибудь при работе руками, ручным способом. Второе значение рассматривается как переносное с неодобрительной коннотацией и означает проделку, махинацию [17]. Проанализируем значение слова Manipulation в немецком языке:

...im 18. Jahrhundert entlehnt aus dem französischen manipulation "Handhabung"; dieses stammt von dem französischen manipule "eine Handvoll”; dies aus dem lateinischen manipulus; bezeichnete zunächst eine Handhabung oder Behandlung mit einer Handvoll Kräuter oder Substanzen; aus manus "Hand” und plere "vollmachen, füllen” [28]. / Оно происходит от французского (manipule), заимствовано в XVIII веке от латинского manipulus, что означает горсточка. Первоначальное значение в немецком языке было обращение с горсточкой трав или веществ (здесь и далее перевод автора статьи. - С. Х.). Далее происходит расширение значения слова:

- с прямым дополнением, относящимся к неодушевленному предмету: etw. manipulieren - что-нибудь неверно представить, что-нибудь подменить с определенной целью, подделать [34], что-то подменить с целью получить для себя выгоду, сделать что-то с приборами для того, чтобы они стали хуже работать или вообе перестали функционировать [26]; 
с прямым дополнением, относящимся к одушевленному лицу: j-n manipulieren - изменить чье-либо поведение, повлиять на кого-нибудь, чтобы он этого влияния не заметил [34], намеренно воздействовать на кого-нибудь так, чтобы он не заметил этого воздействия, но стал действовать так, как требуется от воздействующего [26].

На основании проведенного компонентного анализа слова Manipulation приходим к выводу, что его этимологическое значение - определенного рода действие при помощи рук. Изменение значения слова привело к возникновению значения: unerwünschte oder verbotene Veränderung von etwas, Beeinflussung von Entscheidungen, ohne dass der Entscheidende sich dessen bewusst ist [28] (нежелаемое или запрещенное изменение, такое воздействие на принятие решений, что принимающий решение этого воздействия не осознаёт).

Вернемся к термину Manipulation в трактовке М. Шварц. Исходным тезисом является утверждение о том, что при восприятии перцептов внешнего модуса когниции происходит изменение схем высшей степени абстракции в долговременной памяти. Можно манипулировать чем-то, а можно манипулировать кем-то. Можно манипулировать предметами, картинками, названиями, схемами, фреймами. А можно манипулировать человеком. Человек, воспринимающий перцепты, в силах изменить схемы высшей степени абстракции, он принимает решение в убеждении, что это его решение, не всегда понимая, что он несамостоятелен в принятии решения. Такое положение вещей позволяет утверждать, что всякая репрезентация есть результат воздействия со стороны, а определенного рода действия с предметами, схемами, фреймами есть манипуляция.

Схемы высшей абстракции или репрезентации, фреймы присутствуют в ментальной модели мира внутреннего модуса когниции, перцепты проникают в ментальную модель мира человека из внешнего модуса когниции. Причем они разные там и там. Познание происходит в тот момент, когда часть перцептов внешнего модуса совпадает с репрезентациями внутреннего модуса, а часть не совпадает. Действительно ли эти изменения происходят без осознания изменений?

Если признать, что ментальная модель мира - это всегда внутреннее состояние организма [33, S. 44], то внутренний модус когниции, скорее всего, представляет собой процесс внутренних когнитивноконструктивных достижений человека, а внешний модус когниции в этом случае должен представлять собой процесс когнитивно-конструктивных достижений человека в позиции наблюдателя. Тогда можно утверждать, что акт познания есть процесс, базирующийся на имеющемся внутреннем состоянии, проецируемом одновременно на внешние факторы коммуникации. При этом внешние факторы коммуникации существуют автономно, вне зависимости от внутреннего состояния человека. Как только он начинает их познавать, обе системы приходят во взаимодействие.

Восприятие, следовательно, представляет собой точку, в которой сходятся два способа познания объективного мира: перцептивная деятельность человека и языковая система, выполняя одну и ту же роль - роль орудия познания. Первый способ - на перцептивном уровне, второй - на концептуально-языковом. И те и другие знания участвуют в формировании языковой картины мира, коррелирующей с ментальной моделью мира. Последняя находится в диффузном состоянии и представляет собой то самое внутреннее состояние, тождественное опытному знанию. Именно на него может оказываться влияние. Так происходит наложение одного модуса когниции на другой, в результате которого возникает возможность манипулировать ассоциациями, образами, перцептами, презентациями.

В данном контексте М. Шварц вводит термин Manipulierbarkeit, производный от термина Manipulation, для того чтобы отличать один модус от другого. Грамматическое значение суффикса -bar в немецком языке: nachgestelltes Wortbildungselement zur Ableitung eines Adjektivs von einem Verb (суффикс для образования отглагольного имени прилагательного) [35].

Лексическое значение суффикса -bar в немецком языке: zum... fähig; zum... geeignet; geeignet... zu werden; in der Lage zu...; in der Lage... zu werden (быть способным к...; иметь склонность к...; быть в состоянии, стать готовым к...).

Грамматическое значение суффикса -kеit в немецком языке: Suffix zur Bildung abstrakter Substantive aus stets mehrsilbigen Adjektiven, die so entstandenen Substantive sind stets feminin [Ibidem] (суффикс, используемый для образования абстрактных имен существительных, как правило, из многосложных имен прилагательных, образованные таким образом имена существительные, как правило, относятся кженскому роду).

Выбор термина Manipulierbarkeit продиктован, нам думается, необходимостью показать особый аспект взаимодействия двух модусов познания, при котором приходится быть способным к такому действию с перцептами и репрезентациями, когда можно выбирать или набирать из множества потенциально возможных один или несколько значимых для данного речевого акта в данной коммуникативной ситуации. Значение глагола манипулировать, скорее всего, не имеет в данном случае отрицательной коннотации. Но она может приобретаться в процессе формирования ментальной модели мира в том случае, если схемы высшей степени абстракции активны при воздействии на принятие решений о сути ментальной модели мира до такой степени, что человек, реконструирующий перцепты типа COVID-19 и коронавирус, не осознаёт воздействия, оказываемого на него извне, и ему кажется, что он принимает самостоятельное решение оставаться в изоляции от общества.

\section{Заключение}

Таким образом, мы приходим к следующим выводам. Краткий обзор разных взглядов на трактовку процессов структурирования знания показал, что дихотомия ПАМЯТЬ - ВОСПРИЯТИЕ лежит в основе когнитивно- 
реконструктивных достижений человека, результатом которых становятся схемы высшей степени абстракции. Обыденный (материальный) мир противопоставлен ментальному миру, в свою очередь, ментальный мир можно представить в двух ипостасях - отображенный и отображаемый. В отображаемом ментальном мире активизируются перцепты внешнего модуса когниции, в то время как в отображенном ментальном мире хранятся репрезентации в виде концептов как структуры знания об объектах, предметах и в виде фреймов как структуры знания о типизированных ситуациях обыденного сознания. И концепты, и фреймы принадлежат внутреннему модусу когниции. Таким образом, ментальный мир в двух модусах когниции представляет собой реконструкцию обыденного (материального) конструируемого мира. Анализ языкового материала в национальном газетном корпусе русского языка позволяет утверждать, что в ментальной модели мира внутреннего модуса когниции концепт ЗДОРОВЬЕ может быть структурирован фреймами, одним из которых является фрейм сохранение. Для его идентификации использован фреймовый анализ в виде стратегических вопросов и доказано, что сохранение имеет статус фрейма в концепте ЗДОРОВЬЕ. Этот фрейм активизируется в условиях введения в коммуникативное языковое сообщество перцепта COVID-19 и противопоставляется фрейму уничтожение. Ментальная модель мира структурируется перцептами и репрезентациями, последние - концептами и фреймами при условии, что часть этой модели имеет прототипический характер, а часть - индивидуально-специфический. Отсюда концепт ЗДОРОВЬЕ у каждого свой, концепт САМОИЗОЛЯЦИЯ также индивидуально специфичен, перцепт COVID-19 находится на пути когнитивной реконструкции в репрезентацию, в процессе познания, которое представляет собой прежде всего процесс концептуализации. Ментальная модель мира находится в тесной корреляции с термином манипулирование или манипуляция. Манипуляция человеком, а точнее его сознанием, возможна при условии, что в ментальную модель мира восприятия вводятся фреймы в виде репрезентаций, диктующих необходимость их принятия на определенных условиях. Манипулирование вводится в семантическую компетентность человека, в результате чего он становится зависимым от перцептов. Средства массовой информации становятся источником подмены перцептов с целью получения определенной выгоды, которая имеет следствием махинации с сознанием человека, которое работает хуже или вообще перестает функционировать и изменяет поведение человека. Часть перцептов внешнего модуса когниции совпадает с репрезентациями внутреннего модуса когниции, а часть не совпадает, и эта несовпадающая часть представляет собой ту часть ментальной модели мира, которая является ментальным пространством, в котором возможно манипулирование перцептами и презентациями.

Перспективы дальнейшего исследования мы видим в подробном анализе когнитивно-конструктивных достижений человека, активизирующихся в результате действия механизмов восприятия, номинации и памяти на основе детального описания фреймов, структурирующих концепты ЗДОРОВЬЕ, САМОИЗОЛЯЦИЯ, участвующих в формировании ментальных моделей мира когниции современного этапа развития человечества.

\section{Список источников}

1. Болдырев Н. Н. Когнитивная семантика. Тамбов: ТГУ, 2000. 123 с.

2. Болдырев Н. Н. Концепт и значение слова // Методологические проблемы когнитивной лингвистики: сборник статей / науч. ред. И. А. Стернин. Воронеж: ВГУ, 2001. С. 26-27.

3. Воркачёв С. Г. Лингвокультурология, языковая личность, концепт: становление антропоцентрической парадигмы в языкознании // Филологические науки. 2001. № 1. С. 81-92.

4. Гуссерль Э. Собрание сочинений: в 3-х т. М.: Гнозис; Дом интеллектуальной книги, 2001. Т. II. Ч. 1. Логические исследования. $471 \mathrm{c.}$

5. Карасик В. И. Лингвокультурный концепт как единица исследования // Методологические проблемы когнитивной лингвистики: сб. науч. тр. / под ред. И. И. Стернина. Воронеж: ВГУ, 2001. С. 75-80.

6. Карасик В. И. Языковой круг: личность, концепты, дискурс. Волгоград: Перемена, 2002. 477 с.

7. Кубрякова Е. С. Краткий словарь когнитивных терминов. М.: Лев Толстой, 1996. 248 с.

8. Кубрякова Е. С. Процессы транспозиции в концептуализации и категоризации мира // Лингвистика как форма жизни: сборник статей. Кемерово, 2002. С. 30-34.

9. Лихачев Д. С. Концептосфера русского языка // Известия Российской академии наук. Серия литературы и языка. 1993. Т. 52. № 1. С. 3-9.

10. Национальный корпус русского языка [Электронный ресурс]. URL: https://ruscorpora.ru/new/ (дата обращения: 22.01.2021).

11. Петкау А. Ю. Концепт ЗДОРОВЬЕ: модификация когнитивных признаков (по данным газетных и рекламных текстов советского и постсоветского периодов): автореф. дисс. ... к. филол. н. Екатеринбург, 2015. 27 с.

12. Плотникова С. Н. Концепт и концептуальный анализ как лингвистический метод изучения социального интеллекта // Вестник Иркутского государственного лингвистического университета. Серия «Филология». 2012. № 2 (18). С. 193-200.

13. Попова З. Д., Стернин И. А. Основные черты семантико-когнитивного подхода к языку // Антология концептов: в 2-х т. / под ред. В. И. Карасика, И. А. Стернина. Волгоград: Парадигма, 2005. Т. 1. С. 7-10.

14. Степанов Ю. С. Константы. Словарь русской культуры. Опыт исследования. М.: Школа «Языки русской культуры», 1997. 824 с.

15. Степанов Ю. С. Концепт ПРИЧИНА и два подхода к концептуальному анализу языка - логический и сублогический // Логический анализ языка. Культурные концепты: сборник научных трудов. М.: Наука, 1991. С. 5-14. 
16. Сэпир Э. Грамматист и его язык // Языки как образ мира: антология. М. - СПб.: АСТ; Terra Fantastica, 2003. C. $139-156$.

17. Толковый словарь Ожегова [Электронный ресурс]. URL: https://slovarozhegova.ru/ (дата обращения: 03.01.2021).

18. Уорф Б. Отношение норм поведения и мышления к языку // Языки как образ мира: сборник. М. - СПб.: АСТ; Terra Fantastica, 2003. C. 202-219.

19. Фурс Л. А. Уровни категоризации в синтаксисе // Горизонты современной лингвистики: традиции и новаторство: сб. в честь Е. С. Кубряковой. М.: Языки славянских культур, 2009. С. 312-319.

20. Чернейко Л. О. Гештальтная структура абстрактного имени // Филологические науки. 1995. № 4. С. 73-83.

21. Чернейко Л. О. Лингво-философский анализ абстрактного имени. М.: МГУ, 1997. 320 с.

22. Busse D. Linguistische Epistemologie. Zur Konvergenz von kognitiver und kulturwissenschaftlichen Semantik am Beispiel von Begriffsgeschichte, Diskursanalyse und Frame-Semantik // Sprache - Kognition - Kultur. Sprache zwischen mentaler Struktur und kultureller Prägung / hrsg. von H. Kämper, L. V. Eichinger. Berlin - N. Y.: De Gruyter, 2008. S. 73-114.

23. Fraas C. Gebrauchswandel und Bedeutungsvarianz in Textnetzen. Die Konzepte Identität und Deutsche im Diskurs zur deutschen Einheit. Tübingen: Narr, 1996. 175 S.

24. https://www.google.com/search (дата обращения: 25.01.2021).

25. Lakoff J. Philosophy in the Flesh: The Embodied Mind and Its Challenge to Western Thought. N. Y.: Basic Books, 1999. $624 \mathrm{p}$.

26. Langenscheidts Großwörterbuch. Deutsch als Fremdsprache: das neue einsprachige Wörterbuch für Deutschlernende / Herausgeber Professor Dr. D. Götz, Professor Dr. G. Haensch, Professor Dr. H. Wellmann. Auflage 8. Berlin - München: Langenscheidt KG, 1997. 1213 S.

27. Lyons J. Semantics: in 2 volumes. L.: Cambridge University Press, 1977. Vol. 1. 371 p.

28. Manipulation [Электронный ресурс]. URL: https://www.wortbedeutung.info/Manipulation/ (дата обращения: 02.02.2021)

29. Minsky M. The Society of Mind. N. Y.: Touchstone, 1986. 346 p.

30. Palmer Stephen E. Fundamental Aspects of Cognitive Representation // Cognition and Categorisation / ed. by E. Rosch, B. B. Lloyd. N. Y. - Hillsdale: Erlbaum, 1978. P. 259-303.

31. Rosch E. Principles of Categorization // Cognition and Categorisation / ed. by E. Rosch, B. B. Lloyd. N. Y. - Hillsdale: Erlbaum, 1978. P. 27-48.

32. Schwarz M. Einführung in die Kognitive Linguistik. Tübingen - Basel: Francke, 1996. 238 S.

33. Schwarz M. Kognitive Semantiktheorie und neuropsychologische Realität. Repräsentationale und prozedurale Aspekte der semantischen Kompetenz. Tübingen: Niemeyer, 1992. 163 S.

34. Wahrig. Wörterbuch der deutschen Sprache. München: Deutsche Taschenbuch Verlag GmbH \& Co. KG, 1997. 1152 S.

35. Wikiwörterbuch Wictionary [Электронный pecypc]. URL: https://de.wiktionary.org/ (дата обращения: 02.02.2021).

36. Ziem A. Frames und sprachliches Wissen. Kognitive Aspekte der semantischen Kompetenz / hrsg. von E. Felder; wissenschaftlicher Beirat: M. Hundt, W.-A. Liebert, Th. Spranz-Fogasy, B. Wanning, I. H. Warnke, M. Wengeler. Berlin N. Y.: Walter de Gruyter, 2008. 485 S.

\section{Информация об авторах | Author information}

RU Хахалова Светлана Алексеевна ${ }^{1}$, д. филол. н., проф.

${ }^{1}$ Иркутский государственный медицинский университет

EN Khakhalova Svetlana Alexeewna ${ }^{1}$, Dr

${ }^{1}$ Irkutsk State Medical University

${ }^{1}$ ipswet@mail.ru

\section{Информация о статье | About this article}

Дата поступления рукописи (received): 03.01.2021; опубликовано (published): 30.04.2021.

Ключевые слова (keywords): перцепт; репрезентация; фрейм; концепт; ментальная модель мира; percept; representation; frame; concept; mental world model. 